\title{
Keep going: career perspectives on ageing and masculinity of self-employed tradesmen in Australia
}

\author{
TERESA MARCHANT* \\ Griffith Business School, Griffith University, Australia
}

AQ1 1 Received 19 June 2012; accepted 20 May 2013

The ageing workforce has implications for skills retention and equity in construction and ageing of self-employed tradesmen. The aims here were to define older tradesmen and present their experience of ageing along with the implications for masculinity. Ageing, the ageing workforce and construction management informed this conversation about diversity and skills shortages, how tradesmen negotiate ageing, the way it is perceived and how it impacts on masculinity. A phenomenological research design, with 20, in-depth interviews from independent tradesmen was deployed. Older tradesman defined themselves by physical capacity to work, rather than chronological age. Self-initiated strategies increased longevity and consisted of work adjustments such as paying for extra labour and machines and scheduling less onerous work. If widely adopted, such accommodations for the mainstream construction workforce might shift the masculine culture of the industry for specific equity groups. There were numerous possibilities for alternative work, but many disadvantages were identified. Suggestions for the industry about retention included self-care and personalized work adjustments. Recommendations for individuals included proactively planning retirement, particularly in terms of superannuation and other non-housing investment alternatives.

$2 \mathrm{AQ2}_{\curlywedge}$ Keywords: Ageing, masculinity, self-employment, tradesmen, work adjustments.

\section{Introduction}

The ageing workforce and skills shortage constitute one perspective on the phenomenon of ageing tradesmen in Australia. Another perspective consists of equality, diversity and inclusion in construction. Strategies for continuing the inclusion of older, selfemployed tradesmen are investigated. It could be argued that males represent the norm with which others are forced to comply and that studying this cohort simply serves to perpetuate existing hegemonies. However, there are theoretical and business case reasons for studying them. Since the industry is predominantly peopled by males who are ageing, there is value in retaining their skills, even if the masculine culture they subscribe to may be less than desirable. Indeed, accommodations made for ageing men might advance broader diversity and inclusion goals. The strategies that older tradesmen use to perpetuate their own involvement in the industry, despite no longer having the same physical capital, may throw light on how the industry could be changed to accommodate and be more conducive to other groups, such as those with lesser physical strength or with a disability.

A further research gap exists in that the ageing workforce literature doesn't address independent tradesmen. Perspectives in the construction industry tend to be limited to organizational views. Accessing self-employed tradesmen for research is difficult since they are not employed in organizations, do not belong to unions and are not engaged in formal trade, business or other associations. Yet, they constitute the backbone of domestic housing construction and maintenance. How then can this vital cohort be understood and retained? Exploratory interviews with 20 , self-employed tradesmen in the domestic construction industry on Australia's east coast are reported. Literature on ageing, the ageing workforce and masculinity is first briefly explored, followed by

*Author for correspondence. E-mail: t.marchant@griffith.edu.au 
ageing in the construction industry and then the narrower Australian context. Next the phenomenological, qualitative research design used to access these tradesmen is outlined, followed by key findings and analyses which consist of five ageing themes, along with implications for the masculinity literature. The discussion centres on defining age and strategies to improve the retention and experience of ageing tradesmen on task, career and financial grounds.

10 Limitations and opportunities for future research fol$\mathbf{A Q 3}_{\wedge}$ low, before the conclusion is presented.

\section{Ageing and the ageing workforce}

Ageing is a fundamental component of human experience and questions about ageing are significant to understanding most aspects of life. It is an inevitable biological process, represents the chronological record of individuals' existence since the date they were born and thus is not solely a social construct. However, ageing has greater significance, marking the notewor-

20 thy processes of physiological decline, including an increased incidence of disability, changes in social and economic circumstances and differences between cohorts or generations (Arber et al., 2003; Australian Bureau of Statistics, 2011a). Living into later old age will become a well-accepted social phenomenon. Ageing's actualities should be explored further to avoid misapprehending the process (Fleming, 1999). Research should draw on individuals' experiences, rather than extrapolate from large datasets or rely on media images (Arber et al., 2003). Within this general context of ageing, of special interest in the management literature is the ageing workforce. All industrialized countries have an ageing workforce (Armstrong-Stassen and Templer, 2005). This has

35 been a concern for nearly two decades (Sterns and Miklos, 1995).

\section{Defining older workers}

Despite agreement about the significance of the ageing workforce, definitions of older workers are 'fuzzy'. The gerontology, sociology and management literature disagrees on what constitutes 'old', as does government policy. In the management literature, older workers are defined as those from age 40 or 45 . Studies in organizations may consider workers as young as 40 to be older (Kooij et al., 2008), whereas labour market literature may focus on workers who are 50 or 55 . In gerontology and sociology the chronological marker tends to be set at 65 (Fleming, 2001). This 25-year discrepancy is significant in that 50 it suggests different disciplinary perspectives are not studying the same phenomenon.
Similarly, policy and practice in Australia are inconsistent. The Australian Bureau of Statistics identifies mature age workers from 45 (Australian Bureau of Statistics, 2005), yet various regulations imply different ages. For example, in one Australian state, the Office for Ageing (2010) uses 55 as a cut-off for mature workers, but also discusses a range of (shifting) national guidelines such as when the government pension can be accessed. The pension qualifying age is scheduled to increase from 65 to 67 for both men and women between 2017 and 2023 (Australian Bureau of Statistics, 2011b). Other practical definitions include when workers' compensation is no longer available (65), when superannuation can be accessed (55 or older depending on the cohort and gender) and the mature age worker tax offset (55) (Office for Ageing, 2010).

Applying the term 'older' to workers who are relatively young chronologically, risks the attributions and limitations of very old individuals being extrapolated to those who are only in middle age, relative to the total life course and still capable, with potential for discrimination and under-utilization of valuable human resources. Perceptions of what constitutes 'old' determine individual responses to ageing, including social perceptions and potential discrimination (Fleming, 1999). This has been experienced, for example, by older male workers. In one study based on interviews, men who were 45 years or older, who had their positions made redundant did not see themselves as old, but did think that others perceived them this way and thus that their age was a problem (McDaniel, 2003). It would have been interesting to follow up on these men and see how their perceptions of masculinity changed depending on whether they regained employment.

\section{Ageing and masculinity}

Hegemonic masculinity distinguishes men who live up to the cultural ideal or the dominant, privileged stereotype and therefore attain higher status, control or power. Other masculinities are subjugated. Traits of hegemonic masculinity may include physical strength and endurance, independence, control, being the breadwinner, striving at work and executing skillsbased activity (Connell, 1995). Performance and aggression can be added to this description (Comeau and Kemp, 2007).

However hegemonic masculinity is relative to the social relations in operation in particular contexts. The intersection of ageing and gender power relations has been relatively under-researched and it is important to include older men as mainstream rather than 'other' in the discussion of masculinity (Calasanti, 
2003). The growing literature on men and masculinity has ignored later life because ageing is accompanied by a form of masculinity considered inferior to hegemonic masculinity (Varley and Blasco, 2000). There is an emerging body of literature on this issue even if it is relatively new (van den Hoonaard, 2007). The literature on masculinity and loss of physical performance through illness or disability provides some insights because loss of physical performance is also associated with ageing.

Where hegemonic masculinity based on physical performance cannot be achieved, for example in the case of disability or illness, men may redouble their efforts to perform in other areas, redefine masculinity or reject physical stereotypes. A decline in strength may be offset by an increase in skill (Connell, 1995). Similarly, Hearn (1994, 1996) suggests that increases in wisdom associated with ageing may offset physical decline. Connell (1995) does not address ageing and masculinity. However, it has been proposed that ageing may result in new, softer forms of masculinity due to reductions in male hormones and the need to adapt to changing roles and relationships, although these effects might be moderated for different individuals by interactions in social contexts (Arber et al., 2003). The dilemma of masculinity for old men is not limited to one country, culture or component of men's lives (van den Hoonaard, 2007).

Where empirical research on masculinity and ageing has been conducted, three essential components defined masculinity for interviewees in van den Hoonaard's (2009) study of 26 widowers aged 56 to 91: being in a heterosexual relationship, being young and being employed. Economic independence and autonomy are vital for maintaining masculinity in later life, but for those men who cannot maintain these traits then changing forms of masculinity might be evident (Arber et al., 2003). It might be expected that both ageing and no longer being employed would pose significant threats to men's perceived masculinity, due to the embeddedness of age issues in a masculine work situation (Comeau and Kemp, 2007). Therefore of interest here is whether ageing tradesmen still attempt to live up to hegemonic cultural ideals or whether ageing renders them into the category of subordinated masculinity.

\section{Ageing in construction}

The experience of ageing, male, self-employed tradesmen in the construction industry is significant for a number of reasons. There are gaps in the literature and also a number of facets to this experience. Overall, the construction management literature is limited regarding ageing, yet the ageing workforce is important from the perspective of skills retention. In terms of equity and diversity, older workers form an additional group of interest, although this is largely unacknowledged. Workers with a disability are also a diversity group and there is a relationship between ageing and disability; although the two are not synonymous, they tend to be treated as such. Since males are the mainstream of the construction industry workforce, it can be argued that attending to them can result in a widespread impact. Finally, there is the issue of ageing self-employed tradesmen. Since they are self-employed they may not be 'captured' by organizational research perspectives and methods. The following addresses each of these points in turn.

There is little management literature on ageing in the construction industry. The sector needs to become more age-responsive according to a specialized industry report on the skills shortage (Sweet et al., 2010). This report tends to focus on employ- AQ4 ees rather than independent tradesmen and does not offer practical suggestions for retaining older workers. Skills formation and reproduction in the industry are of concern and Debrah and Ofori (2001) provide a useful analysis of the role of the state in construction skills formation. This analysis would be complemented by an individual perspective. A similar comment could be directed at Forde and MacKenzie (2004) who are also concerned with skills but in this case provide a critique, based on a national survey, of lack of employer training efforts. Older workers have inherent knowledge sets that could be harnessed for mentoring and training (Construction Skills Queensland, 2010), although how this harnessing could be done needs more analysis.

Able-bodied males make up the bulk of workers and from an equity perspective it has been argued that efforts should be made to recruit from a more diverse base (Dainty and Bagilhole, 2005). It is vital to comprehend retention and minimize risks faced on the job by older, male workers (McNair and Flynn, 2006). These workers, from an epidemiological perspective, based on a US meta-analysis, have more severe injuries but not a greater number of injuries (Schwatka et al., 2012). One main critique of this literature, which exhibits diverse theoretical perspectives and thus throws light on the topic from a number of directions, is the relative absence of the tradesman's voice. Further, there is much to be gained from studying ageing males in construction, as any theory and policy developed for them may be broadly applicable in the industry. 


\section{Other equity groups in construction}

At the same time, other diversity and equity groups besides older male workers are of interest in construction. For example, EU cross-national comparisons of numerical data on labour market structures indicate many barriers for women's participation (Byrne et al., 2005). In Bangladesh and Thailand female engineers were interviewed to find organizational policies and practices to create more women-friendly construction workplaces (Hossain and Kusakabe, 2005). Female architects also suffer in the industry (Sang et al., 2007). There are strong business case and equity reasons for developing a more inclusive construction industry workforce. Equity and social justice reasons have been advanced in terms of employing women, ethnic minorities and workers with a disability (Dainty and Bagilhole, 2005). These reasons also apply to older workers, even though age as an equity issue is largely unacknowledged in the construction

20 management literature. One equity group is workers with a disability, who are under-represented in construction. Lingard and Saunders (2004) surveyed Australian construction organizations in one state and found limited evidence of extensive rehabilitation or return to work programmes. Since this survey was employer-based, the employee perspective is absent, as is that of independent tradesmen who are not employees. The literature on ageing in construction tends to focus on disability, which increases with age

30 and is a particular risk factor. For example, Hoonakker and van Duivenbooden (2010) utilized large-scale national secondary data in the Netherlands to focus on occupational risks and disability in the industry. Construction workers have higher rates of disabling accidents and injury, therefore fewer older tradesmen exist, having been forced out of the industry by this risk. However age and disability are not synonymous and the two issues should be treated separately in order that issues associated with ageing, other than disability, can be explored.

Large construction employers do not have a strategic approach to managing the ageing workforce, preferring to operate early retirement schemes, rather than proactive retention measures, despite stated retention difficulties (Brenner and Ahern, 2000). While Brenner and Ahern (2000) provide valuable quantitative details about disability among construction workers, the research was conducted a number of years ago. Deep, broad insights into what lies behind their quantitative data would be useful. It is not necessary to accept the inevitability that tradesmen can't keep working or that older tradesmen don't exist or can't be productive. Finally, there is limited attention given to self-employed tradesmen, despite this being a common employment relations arrangement. There was some early research on self-employed tradesmen (Nisbet and Thomas, 2000) but it was not focused on ageing. Much of the existing literature reviewed above is orientated towards construction workers who are associated with organizations. This is understandable given that it is more feasible to access research participants through organizations; yet investigating the voices and hard-to-capture views of independent, individual tradesmen is an important area for research in order to provide new knowledge about ageing in the construction industry, from individual tradesmen's perspectives.

\section{Age and the construction workforce in Australia}

Turning next to the composition of the ageing Australian workforce in general and the construction industry in particular, across Australia individuals aged 65 and older are projected to make up around one-quarter of the Australian population in the next 50 years (Australian Bureau of Statistics, 2011b). The workforce participation rate of Australians aged 55 and over has increased from $25 \%$ to $34 \%$ over the past 30 years, with most of the increase occurring in the last decade (Australian Bureau of Statistics, 2010). This contrasts with construction which is the sixth youngest industry in Australia, with a mean age of 38.5 and where trades are the youngest group at 36.7 (Australian National Training Authority, 2005). The proportion of workers in the industry drops markedly from the age group 45-54 to the age group 55-59, reducing from $19.5 \%$ to $5.4 \%$ (Australian Bureau of Statistics, 2011b). This suggests that the 50 s may be a critical transition point in terms of staying in or exiting the industry and also that the $30 \mathrm{~s}$ may the time to focus on longevity strategies.

In addition to this age drop off, worldwide, skilled trades are the hardest positions to fill (Manpower, 2010). Australia has been no exception (Bain and Mortimer, 2004). A wave of retirements is pending within five years contributing to a significant loss of expertise and experience from the industry (Construction Training Council, 2012). The current economic uncertainty means softening demand for trades (KPMG Econtech, 2011), with only three construction trades being in short supply, compared to 12 in 2008 (Department of Employment, Education and Workplace Relations, 2012). However, in the longer term, with massive resources projects on the agenda for several Australian states, substantial and sustained demand for trade skills is expected (Construction Skills Queensland, 2010). If business, governments and trade associations work together to alleviate talent shortages in skilled trades, the Australian economy 
may grow and prosper (Karmel and Ong, 2007). Constructive government responses include a concerted effort to attract older tradesmen into the training system (Industry Skills Board South Australia, 2006) and a construction industry training fund which levies large projects (Construction Training Council, 2012). The industry literature tends to focus on attracting and training young workers, rather than retaining older ones. Industry reports and academic literature on how to keep older tradesmen working are difficult to source.

\section{Ageing tradesmen}

15 In the context of ageing, the ageing workforce and the construction industry, ageing tradesmen are of specific interest. They may be more complex than ageing workers in other, less physically demanding occupations. The general issues associated with being an older worker may be exacerbated for tradesmen due to the gradual process of biological decline which may have more salience to and impact on them as they rely on physical capacity to carry out their work. When it comes to physical work or manual labour, the worker's body both assists and hinders working life since it provides the exertion, endurance and physical skills needed to carry out the work, but when fatigue, poor health or injury manifest, the body then presents obstacles to working (Eino, 1958; Casey, 1995). Looking back over previous decades, tradesmen who are old today typically started at age 14 to 17 (Ainley and Clancy, 1983). Compared to other occupations they are likely to have worked for several more years by the time they reach institutional milestones such as being defined as older workers or eligibility for the aged pension. Given the nature and time span of their work, tradesmen may be more physically burnt-out, as well as having accumulated more characteristics associated with a long working life, including disability (Australian Bureau of Statistics, 2011a).

From a practical viewpoint, the discrepancy between what different perspectives consider to be 'old' may be larger. Therefore, it may be that older tradesmen need to be defined at a younger chronological age. On a more positive note, labour market research indicates they may have accumulated more human, social and financial capital (Weller, 2006; Biggs et al., 2012). Thus the research objectives were to explore self-employed tradesmen's perspectives on ageing and masculinity including conceptions of being old, physical demands of the trade experienced over time and options and ideas about staying in or exiting the trade over the longer term.

\section{Method}

An exploratory, phenomenological, qualitative design was pursued with face-to-face, in-depth interviews, in order to study the meaning, represent the views and contribute ideas about existing and emerging concepts (Yin, 2011), of tradesmen's working lives. Given the dearth of existing studies and the nature of tradesmen, with possibly less formal education or limited access to internet technology, an exploratory interview approach was considered suitable. There are a variety of ontological and epistemological research stances (Cassell and Symon, 2004, p. 2) and a qualitative approach adds variety and fresh understandings to a relatively new issue in the construction management literature.

By definition, self-employed tradesmen are difficult to access by conventional research means, as they are not employed in organizations, are not union members and do not form trade or employer associations. Practical considerations limited the number of potential interviewees who were accessible to the researcher. Eventually, 20 tradesmen were recruited from personal contacts of the researcher's colleagues (nine), personal contacts of the researcher (seven), cold calls to trades advertisements in local newspapers (three) and referrals from interviewees (one). Altogether, 30 were invited to participate and 20 agreed, from across three Australian states. Ten were located in cities and the remaining were from regional areas (smaller towns). Trades included builder/carpenter (five), builder/bricklayer (one), plumber (four), carpenter (two), electrician (two), painter (one), plasterer (one), cabinet maker (one), bricklayer (one), tiler (one) and plumber/air conditioning installer (one). Attempts were made to recruit across the range of trades in the construction industry as it was expected that different trades would experience varying physical demands with different implications for ageing. However, personal access and availability to the researcher were the main considerations in determining who was interviewed.

Certain questions about age and time in the trades and other demographics were specific, but overall the interviews were open, wide ranging and highly conversational (Lee, 1999), allowing for findings to be contrasted and compared across the tradesmen and to discover the depth and breadth of issues (Coles, 2008). AQ5 00 This research design means that not all tradesmen responded to the same questions and not all raised the same issues and observations. Hence no attempt was made to quantify responses in regard to the main themes, which in any case is not appropriate for a small-scale, in-depth, exploratory, phenomenological study (Yin, 2011). Eighteen of the interviews took place 
in informal settings (coffee shop, home, social venue), with two conducted on domestic work sites. Interviews 5 were generally half to one hour in length. Interviews were recorded, transcribed and manually processed with template analysis (King, 1998). The aim in processing was to identify 'natural meaning units' from each interview that related to themes in the template and group them under that theme (Lee, 1999, p. 90).

Table 1 indicates descriptive demographics for the tradesmen.

The average age of tradesmen was 51 with a range of 32 to 77 . The average age on commencing the trade was 16 years and 9 months (range 14 to 22). The average length of time in the trade was 31 years, with a range of 16 to 62 . Thus a picture emerged of a typical interviewee who was a 50-year-old, self-employed tradesman or builder who had largely been on the tools for around 30 years, since they were 17 and who was still mostly working on the tools. The original intent was to focus on tradesmen aged 40 or 45 and above based on Australian definitions of the ageing workforce. However, several early interviewees commented on younger tradesmen who suffered difficulties staying in the trade due to physical demands so some tradesmen in their 30s were subsequently included.

\section{Findings and analysis}

When analysing the template and natural meaning units, five main themes emerged. The first was age (what constitutes age, distinctions between ages, stories of legendary older tradesmen and age discrimination). The second was the physical process of ageing and becoming worn out (as the work takes its toll, contrasted with the notion of constructive benefits from working, including a strong message that working as a tradesman keeps you fit). The third theme was a range of strategies to facilitate the desire or need to 'keep going'. The fourth theme was retirement and other options in relation to how long to keep going or when to retire. Finally, the fifth theme was financial considerations. Discussion of each theme follows, with quotations from the interviews which represent typical or in some cases, contrasting or uncommon views, along with analysis in reference to the literature.

\section{Theme one: capacity to keep working is what determines age or being old}

The tradesmen ranged in chronological age from 32 to 77 years, yet there was a consistent theme that none of them was old. Age was clearly not a number. The capacity to keep working distinguished older from younger and was most salient. If the tradesmen had the capacity to keep working or 'keep going', they were not old. Only one referred to himself as old (Plumber, 54) and although the oldest recognized that he was unusual in still working, he still did not identify as old (Builder, 77). Age was interpreted

AQ19 Table 1 Tradesmen's characteristics in terms of trade, age and years 'on the tools'

\begin{tabular}{llccc}
\hline IV & Trade & Age & Age when commenced & Years in trade \\
\hline 1 & Builder/carpenter & 77 & 15 & 62 \\
2 & Builder/carpenter & 52 & $161 / 2$ & 36 \\
3 & Builder/carpenter & 50 & 16 & 34 \\
4 & Builder/carpenter & 53 & 18 & 35 \\
5 & Builder/carpenter & 32 & 15 & 16 \\
6 & Builder/bricklayer & 58 & 18 & 22 \\
7 & Plumber & 39 & 16 & 21 \\
8 & Plumber & 52 & 16 & 36 \\
9 & Plumber & 47 & 17 & 32 \\
10 & Plumber & 54 & 17 & 37 \\
11 & Plumber/air conditioning installer & 41 & 22 & 25 \\
12 & Carpenter & 50 & 17 & 33 \\
13 & Carpenter & 65 & 14 & 43 \\
14 & Electrician & 57 & 17 & 40 \\
15 & Electrician & 65 & 17 & 51 \\
16 & Painter & 52 & 17 & 20 \\
17 & Plasterer & 33 & 18 \\
18 & Cabinet maker & 55 & 19 \\
19 & Bricklayer & 42 & 45 & 16 \\
20 & Tiler & & 24 \\
\hline
\end{tabular}


from a capacity perspective because trade work depends on physical health, strength and skill. Still working on the tools signified a certain capacity for continued hard work:

You can have people who are in their 60 s and still working harder than someone in their 30s. (Electrician, 57)

References were made to even older tradesmen, with an undertone of 'legends', including a father who was still painting at 70 , a friend still building at 75 , builders in their 60s, painters in their $60 \mathrm{~s}$ and a bricklayer in his 60s. In confirmation, there was also mention of younger tradesmen who could not keep going:

They're pretty fit and healthy (older tradesmen known to the interviewee) ... I think young unhealthy guys are weeded out before 40. (Plumber, 39)

Some tradesmen proffered various ideas about how long they would keep going ranging from a few years, through to five, 10 or even 20 years, with the trend appearing to be towards 10 years, even for the older ones.

Generally age discrimination did not appear to be a concern and was only raised by three tradesmen. One currently worked in an organization as an employee and was somewhat concerned about his age when applying for a different position, but the supervisor in charge knew him from previous work (Electrician, 65). Another was the oldest tradesman:

Well the thing that will probably bugger me up is that I won't get work, I'll be seen as too old. (Builder, 77)

Another builder thought that since the business environment was very unfavourable this might give younger tradesmen an advantage in competing for work, but he was happy to let them go to the mines and do the hard work while he picked up the work they left behind in the local area (Builder, 53). Personal networks, reputation and contacts were mitigating factors proffered by these tradesmen as ways to avoid age discrimination. This network of connections with an established reputation and social capital were noted in independent tradesmen in the UK by Nisbet and Thomas (2000). For these Australian tradesmen social capital reduced the risk of age discrimination.

\section{Defining older tradesmen}

Regarding the 'fuzzy' definition of ageing workers in tradesmen who spanned a 45-year chronological age range. Most tradesmen did not describe or consider themselves as old, either because they had the work capacity of younger men or because there were other working tradesmen they knew who were chronologically older. There was a sense that the latter were heroic legends who had the capacity to keep going. Age was defined by the tradesmen's state of endurance, energy, health and fitness and their ability to keep going. It was not about age as a number, but rather about age as physical capacity. Hegemonic masculinity was asserted. Being older as such did not signify subordinated masculinity, rather losing the physical attributes of masculinity did. Even though these tradesmen may manifest subordinated masculinity due to their age, their assertions about capacity to keep working suggest hegemonic masculinity continued to be performed (van den Hoonaard, 2009).

\section{Theme two: it 'wears you out' versus it 'keeps you fit'}

The toll on the body of long years of hard work was widely acknowledged, with several nuanced variations including specific areas of pain or disability, general weariness and, conversely, the assertion that it keeps them fit. Although age was conceived as physical capacity to keep going, it was acknowledged that keeping going took its toll. For example, 'it is too hard on the body', 'it's wearing you out', 'degeneration', 'it wrecks you' and 'your body falls apart'. In terms of specific problems, it appeared there was a long litany of comments about the work's physical impact, but there was little sense of blame, entitlement or complaining. Observations were matter-of-fact statements about the consequences, particularly for knees, backs, shoulders and various other body parts, from repeated use, over a long period of time, including repetitive strain and generally wearing out. One comment that summarized the various views was:

Because when they get to 40 and then their knees start going and their sciatic starts going and their legs start going and they've got a sore back ... maybe they've lost an eye because they ran into steel or they've got cuts and scars all over them and ... like cancer from the sun ... by the time you get to 50 you're blown out, you're worn out. It's like too physical, you're worn out. (Carpenter, 50)

The plumbers mentioned their knees:

Every time you're digging with a shovel you're pushing, your knees are shattering and I think that's why our knees go so bad. (Plumber, 47) 
For one bricklayer the impact was earlier and more severe:

Their hands are probably like mine two years ago, three years ago, my hands were black and the most I could get my hands apart was just like that (indicates limited range of finger movement), they were just callused from there to there and you couldn't do it. (Bricklayer, 42)

An interesting and largely unrecognized (by the tradesmen) dichotomy emerged in discussing the physical impact of doing trade work over an extended period of time. On the one hand was acknowledgement that it is demanding on the body, but on the other there were repeated affirmations that it keeps you fit. This suggests determination to resist transitioning from hegemonic to subordinated masculinity (Connell, 1995). Despite this, it was clear that age was wearying them. Some of the older tradesmen's capacity for sustained hard work was reduced. Two typical examples were:

I know I can't do the stuff I was doing five years ago, it does, it wears you down ... I get home at 4 o'clock and I'm totally stuffed if I've had a big physical day. My wife says 'let's go for a walk' and I say 'no I've had a big day'. (Builder, 53)

You can't work hard all day you just can't put in five huge days like you did when you were $30 \ldots$ you're knackered the next day if you're doing drainage three or four days in a row it, just knocks you around, getting in and out of the trenches. (Plumber, 52)

In terms of work keeping them fit, illustrative comments were:

It's like callisthenics every day stretching, crouching, moving, it's a good workout, I found that it keeps me fit. (Painter, 52)

I have to be flexible for every day, I'm up and down ladders and climbing round, which keeps everything sort of moving and supple. (Electrician, 57)

Some times I think at night that a job sitting down would be OK, but then I think doing a job that's physical does more good than harm. (Plumber, 39)

Having recognized the demands, there were various strategies to sustain engagement.

\section{Theme three: strategies to keep going}

45 Consistent with the notion of age being the physical capacity to keep going, the next theme was strategies utilized to achieve this aim. Three strategies were: attending to physical health; taking on more labour; and numerous adjustments to work tasks, scheduling, selection and execution. Three views emerged in terms of attending to physical health: (1) a laissez faire or typically Australian 'she'll be right mate' majority; (2) a minority, risky medication approach including cortisone injections, frequent use of pain killers, occasional use of steroids and illicit substances; and (3) a proactive, wellbeing minority including aerobic exercise and yoga. The tradesmen exhibited a broad range of body types from slim and wiry to decidedly overweight, accompanied by a mix of attitudes about the need (or otherwise) for physical self-care beyond the exercise and fitness afforded by the work itself. The oldest tradesman was the most unusual and inspiring:

I always felt that because you got older you didn't have to stop doing what you were doing before, so that's why I'm still running. You know but I can appreciate the benefits the running gives me cause it gives me inner strength to sort of keep going ... and it keeps me active and I can bend around and do all. (Builder, 77)

Using additional labour was a second strategy and had advantages and drawbacks. For example, one builder found a low level of competence in the carpenters he tried and this was frustrating. A second conceded that it was necessary on some jobs for him to employ labour to keep going but it added to the job costs and thus reduced his income. A third used a labourer to carry equipment and thus eased the strain on his body.

Thirdly, in terms of a broad range of work adjustments, changing how the tasks themselves were executed enabled some tradesmen to keep doing the same work but do it differently:

You see a lot of old guys plastering who wear the back braces cause over time it does deteriorate. (Plasterer, 33)

I just got to be careful about how I sort of move the body a bit. I use a bucket now to sit on, I've got to position my posture ... and the physio made a big difference. (Plumber/air conditioning installer, 41)

I know what I'm doing to cause my back to get sore ... took me a long time to work that out. I take it very slow, very steady I'm just extra cautious now. (Tiler, 45)

Work scheduling adjustments included working fewer days or completing fewer jobs, and work adjustments also included arranging jobs so there were fewer 
onerous days interspersed with more demanding days:

You just shuffle the jobs around ... some days you might have a week of it you know but then you don't work a full day the next day, a Friday or something like that or you might do a big day then you might have an easy day, like make a few down pipes or something that's less taxing or put a new toilet in for someone. (Plumber, 52)

Job selection adjustments included changing from one type of work to another that was less demanding, for example:

I've also changed tack to where I've gone away from doing the hard yakka of plumbing which is drainage and houses and into maintenance. (Plumber, 54)

Work adjustment also included technical/technological strategies such as using lifting devices on vehicles. Some strategies were combinations in that some tasks were no longer executed and a machine used instead:

One thing I don't do now which I refuse to do and that's dig holes, made that choice a few years ago and said, that's it, no more, never again. I'll get a machine in and pay a couple of hundreds of dollars rather than do it myself. (Builder, 53)

The construction industry is said to be disabling (Clarke et al., 2009), yet age itself should not be considered disabling. Ageing doesn't have to mean the loss of older tradesmen when they have found ways to enable themselves to keep working.

\section{Capacity versus decline}

Some tradesmen exhibited some symptoms of 35 physical decline in older men identified by Marshall (2007), including a decrease in strength or endurance, a lack of energy and some deterioration in work performance. Interestingly, this did not generally detract from their ability to keep working with adaptations. Their long experience, reputation and general 'savvy' about being a tradesman compensated for this decline, as did their self-initiated adaptation strategies. Therefore, the focus should not be on chronological age as such but rather continued capacity for work of each individual. However, finding other options was also a theme.

\section{Theme four: exit options and plans}

Although one main theme was about persisting on the tools, there was some discussion about getting out or finding other options. Of the 20, 13 were still on the tools, two were off temporarily due to disability, two were predominantly builders (i.e. project management) but still on the tools at times and three were working in other occupations. In terms of seeing themselves in a good financial position to change options or retire, only two were clear that they were in a good position, seven had some concerns, six might be in a good position, but it wasn't clear, and for others it was not discussed or was not applicable (younger tradesmen), as shown in Table 2.

Retirement was not an age or a target for most of these tradesmen, whether because they wanted to keep working, had to keep working for financial or family reasons or had already stopped working. There were some negative views on retirement: some recognized the inadvisability of an abrupt end to a lengthy working life with the idea that it is a dramatic change with nothing to occupy their time. It was rare to find responses that might be considered stereotypical Australian views on retirement; however, a few commented on their hopes and desires such as taking it easy by transitioning into a less demanding life, becoming a grey nomad (travelling), playing golf or going fishing. These responses were in a minority.

Between them, when pooled, the tradesmen's suggestions about alternative options represented a long list. However, no one individual had an extensive list for himself. Indeed the options for each individual seemed quite limited, with many downsides or even no options. The perceived options to move off the tools or into a different role to get out before retirement from the younger tradesmen were quite general, for example 'diversifying into something else', 'building an empire' or 'buying houses and renovating them'. The actual options for those already off the tools (permanent or temporary) included: being on a government disability pension, being on (private) income protection insurance and looking around for other options, doing tree lopping and rubbish removal, traffic control on work sites and working in hardware retail. Changed employment arrangements within the industry were also proposed. For example, continuing in a part-time capacity was an option mentioned by a few and one argued for the benefits of being an employee (rather than being self-employed):

Just working for a company you've got a lot of benefits so as you're getting older you've got to think of that. I prefer to work for someone just the benefits
50 
Table 2 Financial position for retirement

\begin{tabular}{ll}
\hline Regarding retirement & Tradesmen positioning \\
\hline In a good position (2) & Builder/carpenter, 52 \\
Not in a good position: some concerns (8) & Builder/bricklayer, 58 \\
& Builder/carpenter, 53 \\
& Builder/carpenter, 50 \\
& Plumber, 52 \\
& Plumber, 47 \\
Possibly in a good position/not clear (5) & Plumber/air conditioning installer, 41 \\
& Carpenter, 65 \\
& Carpenter, 50 \\
& Painter, 52 \\
& Builder carpenter, 77 \\
Not apparently of concern (5) & Electrician, 65 \\
& Electrician, 57 \\
& Plumber, 54 \\
& Cabinet maker, 55 \\
& Plumber 39 \\
& Plasterer, 33 \\
& Bricklayer, 42 \\
\end{tabular}

and the super (superannuation) and the holidays and all that are better. (Electrician, 65)

Other perceived options were common ones that could be considered applicable to most of the tradesmen, such as foreman, buying a franchise or starting another business, retail in some of the major trade suppliers or hardware stores, becoming a representative for an industry supply company, teaching in a technical and further education (TAFE) college, teaching high school technical classes or going to university to study management. Others were unique to an individual's particular circumstances: establishing an overseas business by virtue of an Asian wife, conducting workshops on alternative living or writing another book. Disadvantages of the common options included too much paperwork, too much structure, no control over own time, working indoors, no patience, too independent, loss of status, long hours and low pay as a foreman, retraining which included a number of years with no income while still needing 25 to support a family, no capital to buy or establish a business and lower income.

Of those tradesmen who didn't really know what else they could do or what attractive options there might be, the thought of retiring from or quitting the trade was partly problematic and partly of no great concern, as they were happy to keep going. These views are captured in the following:
Good question, good question, I don't know, I really don't know. ... I'm happy doing what I'm doing at the moment. I really don't know in all honesty. I looked at other businesses and things like that and it's all just too hard. (Plumber, 54)

This indicates the significance of work identity for maintaining hegemonic masculinity (Connell, 1995).

\section{Retirement}

The findings converge with the literature on men's ageing and transition into retirement. Transition into retirement shines a spotlight on their lives (Arber et al., 2003), particularly when those lives are devoted to work. Working life for the tradesmen in this research was well lit and easy to talk about. Any future non-working life or different, non-trade working life was generally a darker spot, where the tradesmen had fewer answers. There is a subversive element to these tradesmen's approach to skill and longevity in that they have maintained an independent, autonomous and generally successful working life for a large number of years despite little or no support, virtually no welfare, hazardous work and no organizational or institutional membership. Therefore strength and identity are garnered from the work. There were positive and negative perceptions and misapprehensions of ageing as per Fleming (2001). The tradesmen appeared to be pushing the envelope 
in their determination to keep going and to not be considered as old. Yet, it is possible to learn from them about how to achieve this longevity. Given that living into later old age will become a well-accepted social phenomenon (Fleming, 1999), then tradesmen working into older age can also prove a source of useful ideas about longevity. Part of the difficulty of embracing other options was caused by financial considerations, the subject of the next theme to be discussed.

\section{Theme five: financial considerations}

Financial considerations had an impact on the feasibility of retiring or changing to other options, if they were available or desirable. The considerations included low priority or significance attached to the aged pension, lack of superannuation and reliance in some cases on investment property. The aged pension did not emerge as a serious option for these tradesmen, but unlike other Australian employed workers, where employers have an obligation to provide superannuation, in the main they lacked superannuation, with rare exceptions:

Luckily I've got a very smart and astute wife and yeah we've rolled over a certain amount into super. (Plumber, 54)
Investment property served as an alternative to superannuation, although these properties were at risk for some. One had already been forced to sell one property due to the difficult business environment (Builder/carpenter, 50). The following comment from another was unusual but illustrated the potential risks:

I had a bit of a cash super and then bought a property ... but now things are getting pretty ugly. I'm about to sell, ... because I need the cash, so I'm selling my super which I was planning on keeping. ... got offered an amount a couple of years ago and I knocked it back and said no it's my super fund I have to hold onto it for the next 20-30 years and now it's come to this because work is sketchy, money is a bit hard, I can't get rid of it, so there goes my super which I've been paying like the last 10 years. (Plumber/air conditioning installer, 41)

Those who had just one investment property with the 'normal' challenges and associated risks could be contrasted with those who had deliberately built, bought or sold a number of properties over the years. Tradesmen who had gone on to become builders seemed more likely to have had a proactive strategy of building up a portfolio of investment properties compared to the few tradesmen who had, where it seemed less strategic. Some had good advice from a young age which they acted on:

I've always built my own houses. I was 18 and I was going to buy a new car and my father said why don't you buy a block of land. So I did, I listened to him. The boom started, then six months after, it was worth $\$ 9500$. I bought it for $\$ 3300$. (Builder/bricklayer, 58)

I made a couple of right decisions a long time ago, built a couple of houses in the right spots ... at the right time ... that's given me opportunity to buy a few houses and fair bit of property. (Builder/carpenter, 32)

When I was with my boss doing my apprenticeship he suggested I buy a block of land which I did, I was 18 or 19. (Builder/carpenter, 52)

In terms of the housing market, the tradesmen were doubly exposed in that their livelihood depended on the ups and downs of the construction industry and, not having compulsory superannuation that employed workers enjoy, their investment in housing, which is natural for this cohort, virtually doubled their risk factors in the housing market.

\section{Discussion}

The main findings revealed that age was considered to be more about physical capacity than a number and the work was demanding but also could be good for physical fitness. Despite this, various adjustments were made to keep going, which was the general intent, partly due to desire and partly due to limited perceived options or lack of financial resources for retirement. Overall, the tradesmen's perspective on ageing was positive in that they mostly still had the capacity to work and thus they weren't really old. The physical demands of around 30 years on the tools were acknowledged in a matter-of-fact way and a desire to persist in work resulted in a number of adaptive accommodations. Alternatives to working in the trade existed but were not highly attractive, except for those tradesmen astute enough to set themselves up financially through property investments. Exit strategies were somewhat limited due to lack of superannuation, but it should be said that around one-third wanted to and intended to keep working into late older age.

\section{Implications for theory}

Older tradesmen may be defined in their 50s
Given that age is a fuzzy concept, there may be some pressure or expectation to determine an age at which 
tradesmen could be considered old. There are risks associated with doing this, including potential for dis5 crimination and a conceptual difficulty in that 'old' is not an age, it is a capacity. However, it would appear that the tradesmen were more likely to be discussing decline in physical capacity in their 50s. Some of these tradesmen were unique in still being engaged in the industry beyond the standard exit age, which for example in Ireland is 58 (Brenner and Ahern, 2000) and in Australia is around 54 when numbers drop off more dramatically (Australian Bureau of Statistics, 2011b). Unlike extant literature for men in general (Thompson, 2006) these men were not in their prime between 45 and 60, since they reported experiencing a decline from around age 50, if not sooner. Therefore a tentative conclusion could be advanced that an older tradesman is one who is in his $50 \mathrm{~s}$, assuming that he has not suffered a specific disabling injury, accident or other condition in the interim. This contrasts with the findings of Comeau and Kemp (2007) in the IT industry where men were defined as older in their $30 \mathrm{~s}$, in a performance environment that related to elite sports, even though there was little evidence of physical incapacity at this age. As Calasanti (2003) indicated the fact that age categories are subjective and constructed does not make them and their consequences less real. This is very evident here.

30 There is no doubt that these tradesmen were experiencing the effects of ageing even if they were doing everything in their power to resist.

\section{Implications for understanding masculinity}

In terms of exploring how men negotiate ageing, the

35 way it is perceived and how it impacts on masculinity, the findings and analysis indicate that these tradesmen negotiate ageing by emphasizing hegemonic masculine traits such as keeping fit, continuing to work, maintaining a work identity and continuing to earn an 40 income. The paradox associated with attempting to maintain hegemonic masculinity in the face of physical decline was evident. Given that most of the tradesmen were still working and had managed to keep going they were asserting hegemonic masculinity while still acknowledging the transition to different but not necessarily subordinated masculinity.

Being old and therefore possibly being subordinated in terms of masculinity was related to loss of bodily function and in this regard accords with the analysis of Comeau and Kemp (2007). However, unlike the IT professionals in Comeau and Kemp (2007) these independent tradesmen generally did not have an 'escape route' into management whereby they could maintain status. Also age differentiation of roles in the independent construction industry did not appear to disadvantage older tradesmen, although this may be different for tradesmen employed in organizations, where the social construction of ageing and masculinity may be more evident. These tradesmen appeared to exhibit behaviour responding to exhortations to not get old identified by Calasanti (2003). There seemed to be social imperatives to resist ageing and maintain hegemonic masculinity.

\section{Implications for policy and practice}

Turning to practical implications, several suggestions are offered including (1) self-application of the Finnish Work Ability Index; (2) general application of AQ6 strategies suggested in this Finnish programme; (3) recognition that the construction industry does not have to be automatically disabling for older tradesmen (4) onsite, applied research to develop feasible versions of the tradesmen's strategies in other work contexts; (5) the possibility that if these adaptations are made for the mainstream (males) the culture might change; and (6) that adaptation strategies be implemented for tradesmen around 45 to 55 years of age, but that also more attention to ageing issues be implemented from the commencement of trade training.

The Finnish Work Ability Index identifies capacity for work and the implications of job demands, including sickness and disability among older construction workers. Two of the main strategies self-initiated by tradesmen in the present research, adjustments to the physical environment and health and lifestyle promotion, matched those in the Finnish work ability promotion programme (Tuomi et al., 1997). The adjustments were generally self-initiated so it would be necessary to find ways to encourage ageing tradesmen to adopt such practices in ways that work for them. These tradesmen had constructive approaches to their own retention and longevity and these approaches could be usefully understood and acted on by larger organizations, given that large employers do not have a strategic or proactive approach to ageing (Taylor and Walker, 1994). These self-employed tradesmen did not have recourse to the 'normal' organizational and institutional support, services and regulations that mitigate problems of ageing for employed tradesmen or indeed the employed in general. Therefore practical, workable, ways need to be found to implement this new knowledge on how to retain ageing male tradesmen.

National or organizational policies to improve retention might ignore or misunderstand the essential workplace dynamics that render such strategies unworkable when it comes to the case of individual tradesmen in the construction industry. That is, hege- 
monic masculinity and the need to appear fit and strong (Hearn, 1994, 1996). Realistic investigation is needed by a researcher collaborating with tradesmen on site about what options are feasible in the business arrangements and work environments that these individuals work in as independent self-employed tradesmen.

\section{Solutions and adaptations}

Suggestions for adaptation include providing alternatives such as: part-time work (fewer days per week), shorter hours (fewer hours per day) and assistance with lifting, digging, carrying and other more onerous and labour intensive elements of the work. How these suggestions would be received in the masculine and confrontational culture of the construction industry is questionable (Hossain and Kusakabe, 2005; Loosemore and Galea, 2008), but culture can change. It would require employers to provide flexibility for the benefit of workers rather than for themselves and there may be some reluctance around this. The construction industry culture that requires women and other nonmainstream groups to fit in (Eliufoo, 2007), might be changed if efforts are implemented to assist what were originally the mainstream group (able-bodied males but who are now ageing and thus moving into a 'diversity or equity' group) to continue fitting in.

The difficulties tradesmen experienced in terms of continued capacity to carry out the work began to manifest in their 50s, given the tradesmen had survived other ravages of the trade to date. Clearly prevention interventions should start on the first day an apprentice commences their trade, but in terms of retaining the current cohort of older tradesmen, then around age 50 may be the time to start assisting and retaining older workers.

Other proposed solutions to some of the identified problems include institutional responses compared to the private ones mostly adopted by these individual tradesmen. National or public interventions could include education about exit options, mandatory financial and career planning for tradesmen in their 30s, compulsory superannuation and an industry future fund. Rather than just focusing on attracting and training young workers, an industry future fund could provide interest free loans and scholarships to retrain in the industry in a less demanding trade or adopt a different occupation outside the trade. This fund would recognize that tradesmen who needed to retrain are likely to be at the age where they have family and other commitments.

In terms of other occupations and options to exit the trade or industry or to retire, the tradesmen appeared to be devoid of informal information from community contacts that could lead to further options (Thiel, 2007, 2012). Therefore ways should be found to inform them about flexible, online, part-time, options for retraining or taking up other occupations (although online information provisions could be challenging for the older tradesmen).

Compulsory superannuation for self-employed tradesmen seems indicated given the dearth of retirement finance. Those tradesmen who had the choice to keep going or to retire seemed to have made astute investments, starting from an early age, compared to those who were required to keep going. Future financial planning could be included in initial trade training. It could also be included in subsequent updates and reclassification. There could be compulsory retraining or parallel training into a new trade, for tradesmen in the most physically demanding trades, as well as ongoing attention to the long-term financial future. This could be tied into licensing requirements. As with continuing professional education (for example continuing professional development points for builders) continuing physical monitoring and an imposed time limit on work in the trade might be tied in with licensing as this may be a way to access this largely independent cohort. However, their very independence may mean that compulsory measures would not be well received.

Also useful would be some form of local 'club', group or association for these tradesmen who are not in unions and not employed in organizations. Such a group would need to be peer-based, not hierarchical and exist for the purpose of mutual support, self-organizing, information-sharing and self-help, going beyond the informal social gatherings they may engage in from time to time, but stopping short of being formal, bureaucratic or dictatorial, where information, advice, ideas about the issues raised in the research could be shared. The only activity that appeared to serve this function and offered these processes were 'trade door' functions organized by a supplier in a city location mentioned by one tradesman.

Self-employed tradesmen enjoy the benefits of autonomy and reasonable rewards but they also carry virtually the entire burden of their own future in terms of work capacity, insurance and financial exit options. This autonomy is important to them but more proactive interventions could have longer-term benefits.

\section{Limitations and further research}

As with all research there are limitations here and consequently options to extend the research, which was confined to a qualitative study of Australian 
5 tradesmen working independently in the construction industry in some parts of the country. One obvious area for further research is women. Female tradespeople were not included since there were generational differences when they became employed in trades in any numbers and thus it seemed even more difficult to source research participants. That is, there may be even fewer older, self-employed tradeswomen.

The research was qualitative and phenomenological. Therefore, one next step could be a quantitative study. Revisiting the tradesmen with a quantitative methodology, now that the main themes have been identified, would enable a more systematic analysis of each issue and topic with each tradesman, with a large and representative sample. However the poten-

20 tial participants are unique, hard to access, not organized and independent. Licensing control bodies in each state might serve as a potential sampling frame for a larger study.

As per previous research, access to a larger group for a quantitative study could be achieved via employer organizations in the industry or through unions. However such tradesmen may not be similar to those in the current research, by virtue of being more closely associated with organizations. Nonethe-

30 less it would make for interesting comparisons. It would be worthwhile to conduct longitudinal research to determine how experiences, attitudes and strategies change over time. Feeding back suggested policies and practical solutions to the tradesmen for their comments and reactions would add authenticity. Other issues that could be researched include the attitudes of older tradesmen to younger ones (with a view to skills retention), changes over time in the skill requirements and technology innovation of the industry, gender attitudes and masculinity of older tradesmen and long-term career progression.

\section{Conclusion}

The ageing workforce is significant for the construction industry, even if it is relatively under-identified.

45 A range of tradesmen in construction, with chronological age from 32 to 77 (average 51), with an average 30 years in the trade, were investigated. These independent tradesmen were committed to 'keep going'. Diminished physical capacity constitutes ageing for older tradesmen. Age discrimination was not a major issue. Trade work both adds to and detracts from the body's capacity to continue working, by accumulating strain and pain, but also endowing physical fitness. Healthy lifestyle activities, replacing the most difficult task demands and changing work schedules were three positive adaptations enabling older tradesmen to keep going. These self-initiated strategies to increase longevity consisted of using machines, extra labour and work adjustments. Altogether, the tradesmen nominated numerous potential options to exit the trade. None had more than one option in mind and overall the opportunities were not that appealing. Desire to keep going was coupled with an absence of viable alternatives and limited retirement financial resources.

Conventional organizations, institutions, employment benefits and support services were largely irrelevant to these independent tradesmen. If industry, government and other stakeholders wish to retain their skills, extraordinary measures are needed. They are only one example of those working in the construction industry; however, they provide insights into how to make employment on larger sites more attractive to older tradesmen, including more flexible options for the hours and days of work, more support for the physical demands of the job and generous superannuation. As with all studies, there was scope for further research including quantitative methods, older female trades and longitudinal projects. The tradesmen's perceptions as independent, older, longlasting, tradesmen have significant potential to add to the retained body of knowledge in the industry.

In summary, there has been limited understanding of the individual perspective on ageing for tradesmen in the construction industry. Older tradesmen define ageing as a loss of physical capacity rather than any particular chronological age, so that set ages in the management and labour market literature are not necessarily applicable. Despite this, with an ageing workforce and an overall skills shortage, measures targeted at tradesmen in their late $40 \mathrm{~s}$ and $50 \mathrm{~s}$ are worthwhile. Older tradesmen can keep working if the required physical capacity is present or is augmented by various strategies. Changes to construction work organization and culture might be needed to accommodate these requirements, but conversely and perhaps ironically, by adapting to the needs of this formerly mainstream, hegemonic group as they age and exit, the industry may well become more favourable to other groups with whom the industry wishes to or is required to engage, such as females and those with disabilities. Those older tradesmen who are still working in the industry may be motivated by maintaining a somewhat tenuous hold on their hegemonic masculinity.

\section{Acknowledgements}

Thank you to Griffith University, Griffith Business School for the Internal Research Grant that funded this project, to Professors Kate Hutchings, Adrian 
Wilkinson, Glenda Strachan and Judith Pringle for input and advice on this project and earlier versions of this paper, and to Heather Stewart and Katrina Radford for research assistance.

\section{References}

Ainley, J. and Clancy, J. (1983) Entry to the skilled trades in Australia: the role of family background and school achievement. Research in Science E Technological Education, 1(2), 145-59.

Arber, S., Davidson, K. and Ginn, J. (2003) Changing approaches to gender and later life, in Arber, S., Davidson, K. and Ginn, J. (eds) Gender and Ageing: Changing Roles and Relationships, Open University Press/McGrawHill Educational, Maidenhead, pp. 1-14.

Armstrong-Stassen, M. and Templer, A. (2005) Adapting training for older employees: the Canadian response to an aging workforce. Fournal of Management Development, 24 (1), 57-67.

Australian Bureau of Statistics (2005) 1301.0 - Year Book Australia, 2005, ABS, Canberra.

25 Australian Bureau of Statistics (2010) Older People and the Labour Market, ABS, Canberra.

Australian Bureau of Statistics (2011a) Life Expectancy Trends - Australia, ABS, Canberra.

Australian Bureau of Statistics (2011b) Population Benchmarks and Labour Force Survey, Cat 6291.0, ABS, Canberra.

Australian National Training Authority (2005) Valuing Australia's Older Workers, ANTA, Brisbane.

Avery, D.R. and McKay, P.F. (2007) Engaging the aging workforce: the relationship between perceived age similarity, satisfaction with coworkers and employee engagement. Fournal of Applied Psychology, 92(6), 1542-56.

Bain, L. and Mortimer, D. (2004) Where are our tradies? A study of skilled trades shortages in the Penrith local government region. Fournal of Economic and Social Policy, 9 (1), 1-15.

Biggs, S., Carstensen, L. and Hogan, P. (2012) Social capital, lifelong learning and social innovation, in Global Population Ageing: Peril or Promise?, World Economic Forum, Stanford, pp. 39-41.

Brenner, H. and Ahern, W. (2000) Sickness absence and early retirement on health grounds in the construction industry in Ireland. Occupational and Environmental Medicine, 57(9), 615-20.

Byrne, J., Clarke, L. and van der Meer, M. (2005) Gender and ethnic minority exclusion from skilled occupations in construction: a Western European comparison. Construction Management and Economics, 23(10), 1025-34.

Calasanti, T. (2003) Theorizing age relations, in Biggs, S., Lowenstein, A. and Hendricks, J. (eds) The Need for Theory: Critical Approaches to Social Gerontology for the 21st Century, Baywood Press, Boston, MA, pp. 199-218.

Casey, C. (1995) Work, Self and Society: After Industrialism, Routledge, London.
Cassell, C. and Symon, G. (2004) Essential Guide to Qualitative Methods in Organizational Research, Sage, London.

Choi, S.D. (2009) Safety and ergonomic considerations for AQ10 an aging workforce in the US construction industry. Work, 33(3), 307-15.

Clarke, L., van der Meer, M., Bingham, C., Michielsens, E. AQ11 and Miller, S. (2009) Enabling and disabling: disability in the British and Dutch construction sectors. Construction Management and Economics, 27(6), 555-69.

Comeau, T.D. and Kemp, C.L. (2007) Intersections of age and masculinities in the information technology industry. Ageing \& Society, 27(2), 215-32.

Connell, R.W. (1995) Masculinities, Allen \& Unwin, Sydney.

Construction Skills Queensland (2010) CSG/LNG Construction Workforce Plan, Construction Skills Queensland, Brisbane.

Construction Training Council (2012) Workforce Development Plan for the Construction Industry, Building and Construction Industry Training Fund, Perth.

Dainty, A.R.J. and Bagilhole, B.M. (2005) Guest editorial. Construction Management and Economics, 23(10), 995-1000.

Debrah, Y.A. and Ofori, G. (2001) The state, skill formation and productivity enhancement in the construction industry: the case of Singapore. International fournal of Human Resource Management, 12(2), 184-202.

Department of Education, Employment and Workplace Relations (2012) Skills Shortages by Occupation and State or Territory: ANZSCO 33 Construction Trades, Labour Market Research and Analysis Branch, DEEWR, Canberra.

Eino, J. (1958) History of Finland's rural trade and AQ12 tradesmen. Scandinavian Economic History Review, 6(1), 101-5.

Eliufoo, H.K. (2007) Gendered division of labour in construction sites in Zanzibar. Women in Management Review, 22(2), 112-21.

Fleming, A.A. (1999) Older men in contemporary discourses on ageing: absent bodies and invisible lives. Nursing Inquiry, 6(1), 3-8.

Fleming, A.A. (2001) Older men 'working it out': a strong AQQ13 face of ageing and disability, Doctoral thesis, University of Sydney, Sydney.

Forde, C. and MacKenzie, R. (2004) Cementing skills: training and labour use in UK construction. Human Resource Management fournal, 14(3), 74-88.

Gale, A.W. (1994) Women in non-traditional occupations: AQ14 the construction industry. Women in Management Review, 9(2), 3-14.

Garrick, B. (2011) The crisis discourse of a wicked policy AQ15 problem: vocational skills training in Australia. Australian Educational Researcher, 38(4), 401-16.

Hearn, J. (1994) Researching men and masculinities: some sociological issues and possibilities. Australian and New Zealand Fournal of Sociology, 30(1), 40-60.

Hearn, J. (1996) Deconstructing the dominant: making the one(s) the other(s). Organization, 3(4), 611-26. 
Hoonakker, P. and van Duivenbooden, C. (2010) Monitoring working conditions and health of older workers in Dutch construction industry. American Fournal of Industrial Medicine, 53(6), 641-53.

Hossain, J.B. and Kusakabe, K. (2005) Sex segregation in construction organizations in Bangladesh and Thailand. Construction Management and Economics, 23(6), 609-19.

Industry Skills Board South Australia (2006) Mature Workers Transition, Industry Skills Board South Australia, Adelaide.

Karmel, T. and Ong, K. (2007) Will We Run out of Young Men? Implications of the Ageing of the Population for the Trades in Australia, National Centre for Vocational Education Research, Adelaide.

King, N. (1998) Template analysis, in Symon, G. and Cassell, C. (eds) Qualitative Methods and Analysis in Organizational Research: A Practical Guide, Sage, London, pp. 118-34.

Kooij, D., Lange, A., Jansen, P. and Dikkers, J. (2008) Older workers' motivation to continue to work: five meanings of age: a conceptual review. Fournal of Managerial Psychology, 23(4), 364-94.

Econtech, K.P.M.G. (2011) Clarius Skills Index, December Quarter, Clarius Group, Sydney.

Lee, T.W. (1999) Using Qualitative Methods in Organizational Research, Sage, London.

30 Lingard, H. and Saunders, A. (2004) Occupational rehabilitation in the construction industry of Victoria. Construction Management and Economics, 22(10), 1091-101.

AQ16 Litwin, H. and Meir, A. (2013) Financial worry among older people: who worries and why?. Fournal of Aging Studies, 27(2), 113-20.

Loosemore, M. and Galea, N. (2008) Genderlect and conflict in the Australian construction industry. Construction Management and Economics, 26(2), 125-35.

40 Manpower (2010) Strategic Migration: A Short-Term Solution to the Skilled Trades Shortage, World of Work Insight, Talent Shortage Survey, August, Manpower, Sydney.

Marshall, B.L. (2007) Climacteric redux? (Re)Medicalizing the male menopause. Men and Masculinities, 9(4), 509-29.

McDaniel, S. (2003) Hidden in the household: now it's men in mid-life. Ageing International, 28(4), 326-44.

A.917 McGuiness, S. and Bennett, J. (2006) Examining the link between skill shortages, training composition and productivity levels in the construction industry: evidence from Northern Ireland. International fournal of Human Resource Management, 17(2), 265-79.

55 McNair, S. and Flynn, M. (2006) Managing an Ageing Workforce in Construction: A Report for Employers, Age Partnership Group, Department for Work and Pensions, London.
Nisbet, P. and Thomas, W. (2000) Attitudes, expectations and labour market behaviour: the case of self-employment in the UK construction industry. Work Employment $\mathcal{E}$ Society, 14(2), 353-68.

Office for Ageing (2010) Employment and Retention Strategies for Older Workers, Office for Ageing, Sydney.

Sang, K.J.C., Dainty, A.R.J. and Ison, S.G. (2007) Gender: a risk factor for occupational stress in the architectural profession?. Construction Management and Economics, 25 (12), 1305-17.

Schwatka, N.V., Butler, L.M. and Rosecrance, J.R. (2012) An aging workforce and injury in the construction industry. Epidemiologic Reviews, 34(1), 156-67.

Steinberg, M., Donald, K., Najman, J. and Skerman, H. AQ18 (1996) Attitudes of employers and employees towards older workers in a climate of antidiscrimination. Australian fournal on Ageing, 15(4), 154-8.

Sterns, H.K. and Miklos, S. (1995) The aging worker in a changing environment: organizational and individual issues. Fournal of Vocational Behaviour, 47(3), 248-68.

Sweet, S. and Pitt-Catsouphes, M. (2010) Talent Pressures and the Aging Workforce: Responsive Action Steps for the Construction Sector, Industry Sector Report 5.1 - July, The Sloan Center on Aging \& Work, Boston.

Taylor, P.E. and Walker, A. (1994) The ageing workforce: employers' attitudes towards older people. Work, Employment $\mathcal{E}$ Society, 8(4), 569-91.

Thiel, D. (2007) Class in construction: London building workers, dirty work and physical cultures. British fournal of Sociology, 58(2), 227-51.

Thiel, D. (2012) Builders: Class, Gender and Ethnicity in the Construction Industry, Routledge, London.

Thompson, E. (2006) Images of old men's masculinity: still a man?. Sex Roles, 55(9), 633-48.

Tuomi, K., Ilmarinen, J., Martikainen, R., Aalto, L. and Klockars, M. (1997) Aging, work, life-style and work ability among Finnish municipal workers in 1981-1992. Scandinavian Fournal of Work Environment and Health, 23 (1), 58-65.

van den Hoonaard, D.K. (2007) Aging and masculinity: a topic whose time has come. Fournal of Aging Studies, 21 (4), 277-80.

van den Hoonaard, D.K. (2009) Widowers' strategies of self-representation during research interviews: a sociological analysis. Ageing and Society, 29(2), 257-76.

Varley, A. and Blasco, M. (2000) Exiled to the home: masculinity and aging in urban Mexico. European fournal of Development Research, 12(2), 115-38.

Weller, S. (2006) Discrimination, labour markets and the labour market prospects of older workers: what can a legal case teach us? Working Paper No. 31, Centre for Strategic Economic Studies, Victoria University, Melbourne.

Yin, R.K. (2011) Qualitative Research from Start to Finish, The Guilford Press, New York. 